\title{
Người giàu không làm việc vì tiền
}

\author{
Asia Blogger \\ Blogspot
}

August 18, 2012

https://asiabloger.blogspot.com/2012/08/nguoi-giau-khong-lam-viec-vi-tien.html 

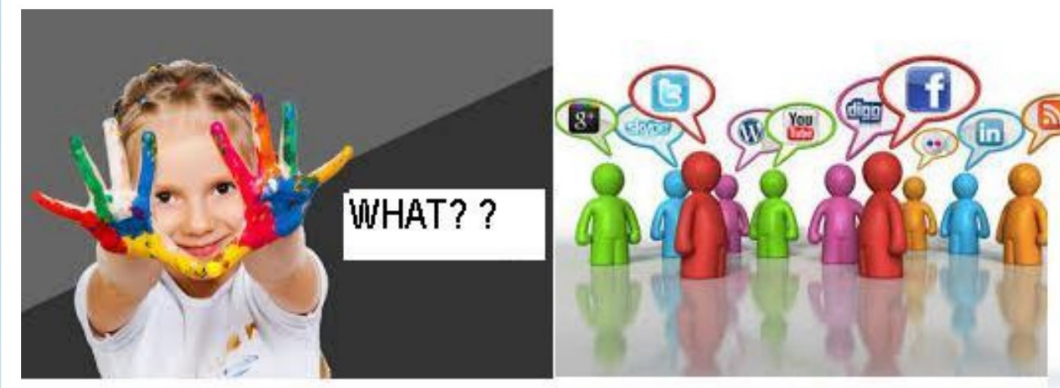

\section{Hãy tìm cho mình một con đường Cơ hội của mỗi người là khác nhau}

----***---Changing The Lives Of Many!

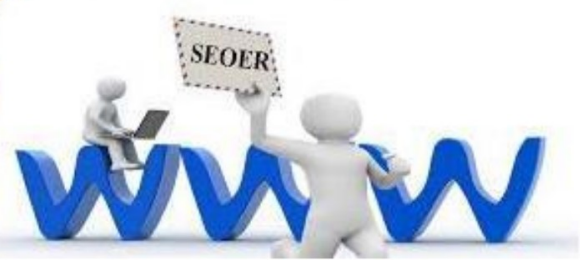

Unknown

Xem hồ sơ hoàn chỉnh của tôi

8.18.2012

\section{Người giàu không làm việc vì tiền}

Xin mượn một câu nói nổi tiếng của người cha giàu trong cuốn sách Rich Dad, Poor Dad của tác giả Robert $\mathrm{T}$. Kiyosaki để làm tựa đề cho bài viết của mình.

Nhưng thật sự thì mình đang muốn nói về một cuốn sách khác, mà mình đang đọc trong thời gian gần đây: "Văn minh làm giàu và nguồn gốc của cải".

reading.jpg

Mình là người may mắn khi được sở hữu cuốn sách rất sớm nhờ một anh bạn nhường lại với lời quảng cáo: Cậu sẽ đọc hết nó ngay trong một đêm cho mà xem! Vì nhiều Ií do mà đã mấy đêm trôi qua mình mới chỉ nhấm nháp được phần đầu của cuốn sách, nhưng chỉ trong 17 trang đầu tiên, tịnh thần khởi nghiệp được tác giả thể hiện trong cuốn sách khiến mình rất thích thú

Tác giả đã mô tả hiện tượng MBA với cái nhìn nghiêm khắc của một nhà làm giáo dục và một nhà quản lí kinh tế. Câu hỏi đặt ra về sự khác nhau giữa việc có được một chứng nhận về trình độ với việc sở hữu các kĩ năng, kiến thức tương ứng với trình độ ấy một lần nữa xoáy sâu vào hiện thực vẫn đang tiếp diễn tại Việt Nam. Tác giả đã chỉ ra được điểm thiếu sót lớn nhất trong việc đào tạo về kinh doanh ở Việt Nam, đó là chưa đào tạo cho người học có được tinh thần kinh doanh, được bắt nguồn từ tinh thần khởi nghiệp. Hoàn toàn đúng khi khẳng định rằng, nếu một người được xác nhận (certificate) đã tốt nghiệp khóa học về quản trị kinh doanh (đại học hoặc sau đại học) chưa thể đứng ra làm kinh doanh được. Cái được chứng nhận sau khóa học là người học đã đạt đến một trình độ nhất định trong việc rèn luyện các kĩ năng, còn việc vận dụng chúng vào thực tế lại là một câu chuyện khác. Chắc chắn rằng không phải ai học quản trị kinh doanh sau đó cũng mở công ty riêng và làm giám đốc, ngược lại không phải giám đốc nào cũng được học qua một khóa học về quản trị kinh doanh. Điểm khác biệt giữa thực tế và lí thuyết chính là lòng dũng cảm, tinh thần dám vân dụng cái đã học vào thực tế muôn màu và không kém phần khắc nghiệt. Theo tác giả, cốt lõi trong các chương trình đào tạo về kinh doanh là việc truyền lửa hay chính xác hơn là gây dựng cho người học một tinh thần kỉnh doanh, các kĩ năng khác chỉ là hỗ trợ cho tinh thần này. Tinh thần dám kinh doanh, dám khởi nghiệp là điều kiện cần thiết nhất, tiên quyết nhất, các kĩ năng bổ trợ là điều kiện đủ chúng ta có thể đứng ra kinh doanh. Nếu bạn chưa được học về quản trị, không sao cả, khi bắt đầu xây dựng công việc kinh doanh thực tế, các kĩ năng của bạn tự khắc sẽ phát triển miễn là bạn có tinh thần cầu thị, học hỏi.

Tiếp tục vài dòng bình luận về chủ đề khởi nghiệp kinh doanh, mình nhớ lại cách đây tròn một năm đã tham gia cuộc thi Sinh viên Khởi nghiệp cùng với nhóm bạn. Ý tưởng chính là tạo dựng một không gian cho có thể thoải mái làm việc, trao đổi, kết bạn, tìm kiếm cơ hội...thông qua mô hình quán cafe. Kingeric-chủ nhân của ý tưởng đã rủ mình cùng bốn người bạn khác tham gia viết dự án để tham gia cuộc thi. Trong hơn một tháng, cả nhóm đã tiến hành hầu như tất cả các công việc cần thiết để chuẩn bị cho việc đưa quán cafe vào hoạt động. Từ những công việc mang tính chiến lược như nghiên cứu khách hàng tiềm năng, xây dựng chiến lược marketing cho đến những việc cụ thể, chi tiết như tìm kiếm địa điểm mở quán cafe, tìm kiếm nhân sự, xây dựng báo cáo tài chính, luồng tiền...Tất cả những công việc đó dù vẫn còn những thiếu sót nhưng đều được cả nhóm thực hiện rất hăng say. Tuy rằng dự án không đạt giải nhưng mình đã phát triển được rất nhiều kĩ năng cần thiết như phân tích, tổng hợp, xây dựng các kế hoạch tác nghiệp trong kinh doanh...Mình cũng nhận ra một điều kinh doanh không dễ (không giống như thông điệp của chương trình Làm giàu không khó) khi có cực kì nhiều công việc phải ra quyết định, phải thực hiện để có thể xây dựng thành công một hệ thống kinh doanh. Nhưng điều lớn nhất là mình đã học được là tinh thần dám nghĩ dám làm, dare to win \& dare to fail hay chính là biểu hiện của một tinh thần khởi nghiệp nóng bỏng và đầy nhiệt huyết.

Những dòng tâm sự của tác giả về tinh thần khởi nghiệp cùng hình ảnh người thương nhân một mình rong ruổi trên chú lạc đà đi tìm kiếm giá trị như một luồng gió mát tiếp tục thổi bùng lên ngọn lửa đam mê kinh doanh của mỗi bạn trẻ. Thế giới kinh doanh rất sôi động và còn rất nhiều việc phải làm, và nên nghiền ngẫm hết anh bạn sách này đã...
Hãy chon cho mình 1 sản phẩm để khởi nghiệp

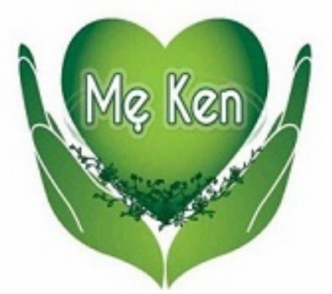

mekenhouse.com tư vấn giúp bạn

\section{Dầu gội thảo dược Me ken}

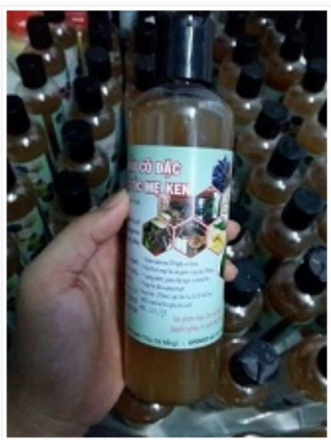

Chúng tôi luôn hoàn thiện để đưa đến khách hàng sản phẩm chất lượng

\section{Quần tất UK- Anh M\&S}

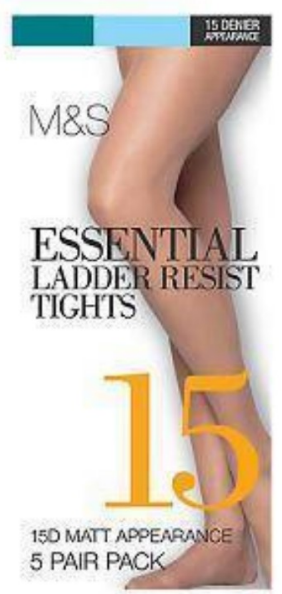

Bạn là phụ nữ không thể thiếu dòng tất nhiều ưu điểm vượt trội này 
Tài liệu tham khảo:

[1] Đào Duy Anh. (1938). Việt Nam văn hóa sử cương. Quan Hải Tùng Thư, Huế (Imprimerie du Mirador).

[2] Vương Quân Hoàng. (2007). Văn minh làm giàu \& Nguồn gốc của cải. Nxb Chính trị Quốc gia, Hà Nội. 